\title{
Monitoring the Spatio-Temporal Dynamics of Vegetation Cover in Mubi Region, Adamawa State, Nigeria
}

\author{
Bulus Luka Gadiga \\ Department of Geography, Adamawa State University, Mubi, Nigeria \\ Email: bulga_mi@yahoo.com
}

Received 20 October 2015; accepted 20 December 2015; published 23 December 2015

Copyright (C) 2015 by author and Scientific Research Publishing Inc. This work is licensed under the Creative Commons Attribution International License (CC BY). http://creativecommons.org/licenses/by/4.0/

(c) (i) Open Access

\section{Abstract}

Studies around the world have shown that vegetation cover is undergoing a dramatic change at various scales. Vegetation is a very important component of the ecosystem, its destruction by whatever means will have an adverse effect on the functional role it plays in the environment. Hence, it is necessary to monitor, conserve and utilize these vital resources sustainably. This study monitors vegetation dynamics in Mubi region with the view to understand the status of vegetation cover and suggest possible conservation measures. The study used regression differencing method of change detection to identify the status and dynamics of vegetation cover in the region. Landsat satellite images were used to create Normalized Difference Vegetation Index (NDVI) using IDRISI software. The NDVI images were subjected to diverse analysis ranging from image registration to image regression, differencing and thresholding. The results from these analysis shows that vegetation cover in the region has witnessed unprecedented degradation. In the period between 1987 and 1999 (12 years) the area that experienced depletion in vegetation cover in the region was 10,501.42 hectares while the period between 1999 and 2015 (16 years) witnessed further depletion to $32,701.77$ hectares. The areas that experienced restoration in vegetation cover in the region from the period between 1999 and 2015 (24,098.94 hectares) have lower areal extent compared with the period between 1987 and 1999 (44,045.80 hectares). This phenomenon is not unconnected with population growth as the region has witnessed explosive growth in the recent past. This growth in population has resulted in higher demand for food to feed the growing population thereby leading to expansion of farmland. High demands for fuelwood by the increasing populace have also contributed to increase in deforestation. Removal of vegetation cover at such a scale will eventually have negative consequences on the ecosystem as its functional roles in the environment are jeopardized. Hence, there is a need to preserve and conserve vegetal resources through sustainable use. 


\section{Keywords}

\section{Vegetation Cover, Degradation, Vegetation Restoration, NDVI, Regression Differencing}

\section{Introduction}

Studies around the world have shown that vegetation cover is undergoing a dramatic change at various scales [1]-[3]. The causes of historic vegetation change in the past years have been viewed by many as a result of both anthropogenic activities and natural phenomenon. Climate has been seen as the primary agent of change in vegetation cover. It is based largely on climate records and the study of repeat ground photography to establish vegetation change. It was suggested that there has been increasing aridity during the past century, accompanied by a shift toward more intense, shorter-duration storms and less precipitation [3].

Studies have also shown that land use has contributed in no lesser measure to vegetation change during the past 150 years. The studies relied on historical descriptions, permanent plot studies, land-use histories, historical maps, newspaper reports, and repeated ground and aerial photography [4].

During the latter half of the twentieth century, the majority of global land cover changes have occurred in the tropical regions, among these, the Sudano-Sahelian zone. Such significant alterations of man's physical environment are environmentally important in as much as they impact the land's resilience and capacity for sustained future use [5]. They may be caused by natural processes [6], but increasingly important is the impact of human land use mainly aimed at producing agricultural products. The study of the vegetation dynamics of an area where increasing changes is taking place is important in order to determine the magnitude of change taking place. This will help in understanding systems and the interaction between the components in the area, thereby bringing out a good management plan for sustainable use of the environment.

The interference between socio-economic alterations, human use of resources, degradation of the environments and negative feedbacks that exacerbate climatic stress [7], have contributed in shaping the changes taking place in the contemporary Sudano-Sahelian landscapes. It was suggested, for example, that cultivation expands onto marginal land [8] [9]; increased degradation of upland fields thereby leading to subsequent abandonment of farmlands [10]. Furthermore, demographic pressure causes decreases in fallow length which results in further expansion of farmlands to feed the growing population, consequently leading to a vicious cycle of degradation [11].

Vegetation is a very important component of the ecosystem, their destruction by whatever means will have an adverse effect on the functional role it plays in the environment. Hence, there is need to monitor, conserve and utilize this vital resources sustainably. Human land use and global climatic change/fluctuation have been responsible in one way or the other in affecting the development of vegetation. Land use/ cover changes may be said to occur as a result of both human and natural induced activities, which interacts with terrestrial ecosystem to influence global changes [12]-[15]. Human use of the land is not a static process but an extremely dynamic one. The unprecedented rates of changes in land cover on the local and regional scales, have led to alterations of global biogeochemical cycles, and loss of productive ecosystems and biodiversity. Such changes if unabated or controlled will lead to serious disruption of the ecological system on which humans depend for their existence. Land cover changes have contributed in many ways to the loss of biological productivity and biodiversity in both terrestrial and aquatic ecosystem. These changes have been defined broadly to include the conversion of lands into croplands and pastures, the abandonment of agricultural lands, deforestation, reforestation, afforestation, shifting cultivation, and urban sprawl [16].

Human history revealed an escalating trajectory of alteration and transformations of the earth that sustains life and the changes over the last 300 years has been to increase the area of agricultural land and decrease the area of forests [17]. The major driving forces behind these changes include rapid population growth and consumption, lack of valuation of ecological services, poverty, ignorance of biophysical limitations, and use of ecologically incompatible technologies. Mubi region is faced with diverse environmental problems which include: soil erosion, deforestation [18], flooding, air pollution and loss of biodiversity which were as a result of the aforementioned driving forces. The ability to forecast land cover change and ultimately predict the consequences of change will depend on our ability to understand the past, present, and future drivers of land cover change. Therefore, adequate and up-to-date information is essential for environmental planning, toward achieving a sustainable devel- 
opment in the region.

The study monitors vegetation dynamics in Mubi region with the view to understand the status of vegetation cover and suggest possible conservation measures.

\section{Study Area and Methodology}

\subsection{Study Area}

The region is located between latitude $9^{\circ} 30^{\prime}$ and $11^{\circ}$ North of the equator and longitude $13^{\circ}$ and $13^{\circ} 45^{\prime}$ East of the Greenwich meridian. It has a land area of $4728.77 \mathrm{~km}^{2}$ and population of 759,045 in 2003 [19]. The region consists of five local government areas namely: Madagali, Maiha, Michika, Mubi North and Mubi South which was delineated on the basis of socio-political factor. The region as used in this study refers to the Adamawa north senatorial district (Figure 1).

Mubi region belong to the highland relief region of Adamawa state [20]. The region has a distinct relief configuration with series of mountain ranges lying along its eastern border with Cameroon. The elevation of the region ranges between $400 \mathrm{~m}$ to $1500 \mathrm{~m}$ above sea level. Its relief can be broadly divided into three zones: the highlands ranges, the highland plains and the low lands.

The region has a tropical wet and dry type of climate, coded as Aw in Koppen's classification. The temperature regime is warm to hot throughout the year, due to high radiation income. However, there are periods of low temperatures during the hamattan season (November-February). The months of May to September constitute the wet season in the region. It has mean annual rainfall of between $900 \mathrm{~mm}$ to $1050 \mathrm{~mm}$. Orographic factor contributes a lot in influencing the pattern of rainfall in the region.

The region is located in the Sudan savannah vegetation zone. The herbaceous community makes up the dominant vegetation in the region, even though it withered out during the dry season. The woody species, therefore, has an important role to play in the environment as it can survive during the dry season when the herbaceous vegetation is not available. However, the natural vegetation has been adversely affected by human use of land in the area. Some of the common indigenous woody vegetation that are found in the region includes; Acacia spp., Adansonia digitata, Anogeissus leiocarpus, Balanites aegyptiaca, Combretum spp., Ficus spp., Tamarindus indica, Terminalia spp. etc.

The dominant drainage system is the Yedzeram River which takes it source from Gella hills flows through the region in a south north direction [20]. It is the major tributary of the Ngada River in Borno state which drains into the Lake Chad. Apart from the Yedzeram River there are other subsystems in the region. The River Mangar which takes its source from Mildu hills, River Pakka and Nguli from Pakka hills and River Tsikari from Zumo hills.

\subsection{Methodology}

The materials used for this study will came from both primary and secondary sources in to determine the past and contemporary patterns of vegetation change. Landsat images (TM 1987, ETM+ 1999 and OLI 2015) were acquired in the same season (November to January). This is in order to reduce phonological difference associated with seasonal variations. They are acquired in such a manner in order to determine changes between 1987 and 2015 (28 years). Vegetation index differencing change detection method was used in detecting areas of change in vegetation cover in the study area.

\subsubsection{Pre-Image Processing}

The selected images were co-registered to the 2015 satellite image. This is in order to correct any geometric error that might have been introduced as a result of different sensors used in acquiring the images. This was suggested by many scholars [21]-[23] that co-registration of images for change detection between different images acquired at different times and with different sensors is necessary for a reliable result. Registration of the images using "Resampling" method was carried out with IDRISI software. All the images used were registered to the Landsat OLI (2015) image.

\subsubsection{Image Processing}

The satellite images were sub-mapped to extract area of interest (AOI) using WINDOW tool in IDRISI software. The sub-mapped images were subjected to image transformation using two bands (RED and NIR band) to pro- 


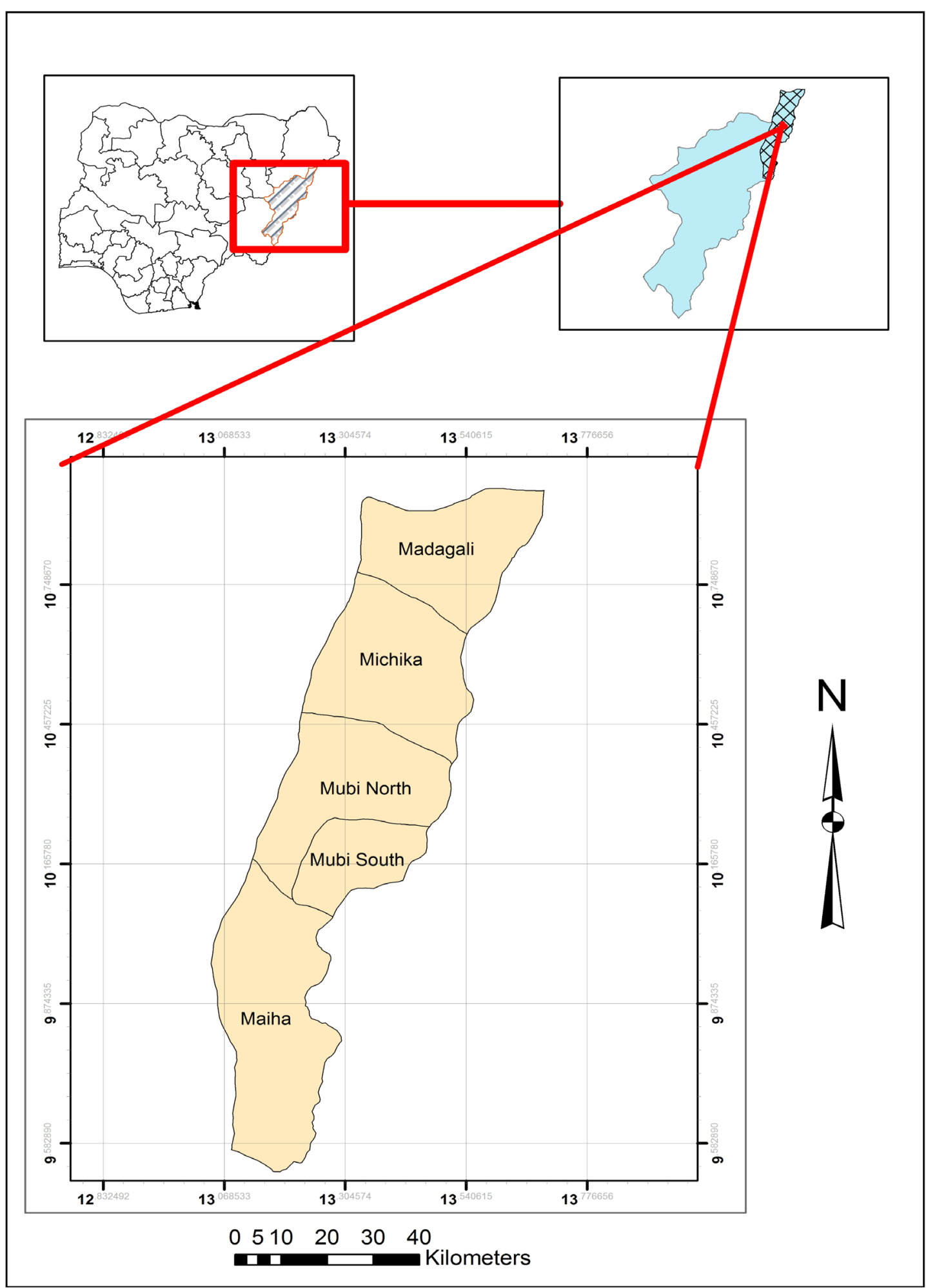

Figure 1. The study area.

duce NDVI images of the study area. Band 3 and 4 were used in creating the NDVI for Landsat TM of 1984 and Landsat ETM+ of 1991 while band 4 and 5 were used for NDVI derived from Landsat OLI of 2015 which represent red and infra-red bands respectively. The NDVI images were derived by the formula in Equation (1). 


$$
\mathrm{NDVI}=\frac{\mathrm{NIR}-\mathrm{RED}}{\mathrm{NIR}+\mathrm{RED}}
$$

where:

NIR = Near Infrared band;

and RED = Red band.

These images were further regressed using the earlier image as independent variable and the later image as dependent variable. This operation helps in correcting the radiometric errors due to seasonal variations in reflectance of the earlier images. The differencing of the images was performed using image calculator with the IDRISI software whereby subtraction of the images were done in pairs (1999-1987; 2015-1999). Furthermore, in order to identify areas of change "Thresholding" was carried out on the subtracted images. The idea behind Thresholding is to determine the deviation from the mean in a normal distribution. In this study, standard deviation (SD) was subtracted from the mean (Mean - 2SD) to determine areas of decrease while the standard deviation was added to the mean (Mean $+2 \mathrm{SD}$ ) to show areas of increase in vegetation cover. The use of 2SD for the thresholding shows that there is 95\% certainty that change has taken place in the area. The difference images were finally reclassified using the parameters gotten from thresholding. Three (3) classes were eventually derived from reclassification. The classes are; No Change which was assigned with the value zero (0), Decrease in vegetation cover (Degradation) with the value one (1) and Increase in vegetation cover (Regeneration) has the value of two (2). The method adopted in this study, is a robust method that assist in identifying hotspots requiring restoration due to high rate of vegetation degradation as well as identifying areas that require conservation.

\section{Results and Discussions}

The result of the study revealed that a total of 10,501.42 hectares have experienced vegetation cover degradation between 1987 and 1999 and further increase in degradation was witnessed between 1999 and 2015 amounting to 32,701.77 hectares. This shows that vegetation cover in the region has witnessed degradation within the period under consideration (Table 1). The results for vegetation regeneration however, show that vegetation re-growth in the region has decreased in the period between 1999 and 2015 in comparison with the period between 1987 and 1999. This affirms that Mubi region is facing continuous vegetation degradation coupled with low vegetation regeneration. Increased demand for food by the growing population influences the way land is used. Generally, the increase in demand for food due to population growth will result in farmland expansion which will consequently contribute to vegetation depletion. Such scenario has led to habitat fragmentation with additional consequences on the flora and fauna which invariably contributes to extinction of vital species in the region's ecosystem. The region is source to many rivers including River Yedzaram which is an important river that feeds Lake Alau located northwest of the region in Borno State. Depletion of vegetation cover in this watershed will contribute to increased upstream erosion thus leading to increased sedimentation and consequent flooding of areas downstream. Alua Dam and rivers downstream are therefore, at risk of silting due to sedimentation. Hence, proper measures for conserving the vegetation cover in the region should be put in place in order to avert the future apocalypse that awaits areas downstream.

Figure 2 and Figure 3 show the pattern of vegetation change and areas undergoing vegetation degradation and regeneration. Understanding the pattern of vegetation dynamics in an area is a vital tool for the conservationist as it helps in pinpointing areas that are undergoing degradation and those experiencing regeneration. Hence by identifying hotspots of degradation, measures can be promptly taken to arrest further degradation while areas of regeneration can be targeted for restoration and conservation. The vegetation index change detection (image regression differencing) method is good in identifying hotspots but not in assessing the rate of change in vegetation cover taking place in the area. However, by identifying hotspots the vegetation in area can be properly monitored and sustainably managed. The result for 1987 and 1999 revealed that vegetation degrada-

Table 1. Area of change in vegetation between 1987, 1999 and 2015.

\begin{tabular}{cccr}
\hline Change & $\mathbf{1 9 8 7}-\mathbf{1 9 9 9}$ (Hectares) & 1999-2015 (Hectares) & Proportion of Change \\
\hline No Change & $1,115,217.06$ & $1,113,031.17$ & -2185.89 \\
Degradation & $10,501.42$ & $32,701.77$ & $+22,200.35$ \\
Regeneration & $44,045.80$ & $24,098.94$ & $-19,946.86$ \\
\hline
\end{tabular}




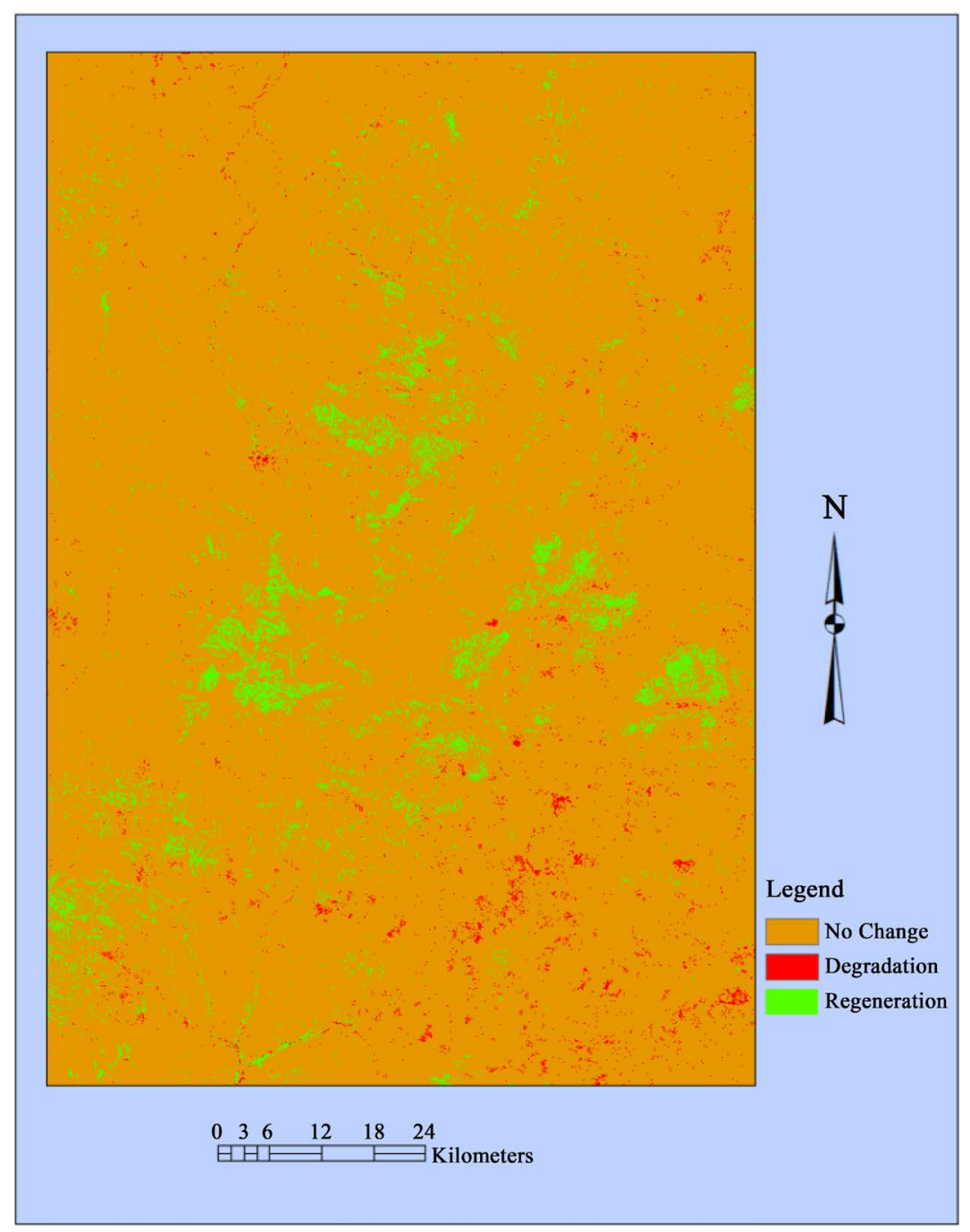

Figure 2. Difference image between 1987 and 1999.

tion is taking place at the southeastern part and along the riparian areas especially in the northwestern portion of the region. This result is in line with the findings by [24] on riparian vegetation degradation in the region.

Restoration of vegetation cover is seen along the highland areas located in the central portion of the map. The pattern seen in this image is influenced by the topography of the area where inaccessibility to the area has limited the use of the land for some types of human activities thereby contributing to regeneration of vegetation cover found there. Figure 2 shows the image regression differencing for 1987 and 1999. The degradation witnessed in the low land areas can be attributed to easy access to the land. However in the period between 1999 and 2015 there was change in the pattern of vegetation change where the southwestern part of the region shows increase in vegetation cover depletion. Generally, the difference image between 1999 and 2015 shows increase in depletion and decrease in regeneration of vegetation (Figure 3). The areas that were degraded in the period between 1987 and 1999 continue to remain degraded in the period between 1999 and 2015. This is because the degraded areas in the previous years have not witnessed regeneration in vegetation cover in the subsequent years.

Studies in the region have further confirmed the degradation of vegetation cover by human activities [24] [25]. The continuous degradation of vegetation in the region calls for proper conservation of the remaining vegetation in the region. Without concerted efforts in conserving the vegetation of the area, the ecological functioning of the ecosystem will be jeopardized thereby affecting the habitats of many species consequently leading to biodiversity loss. 


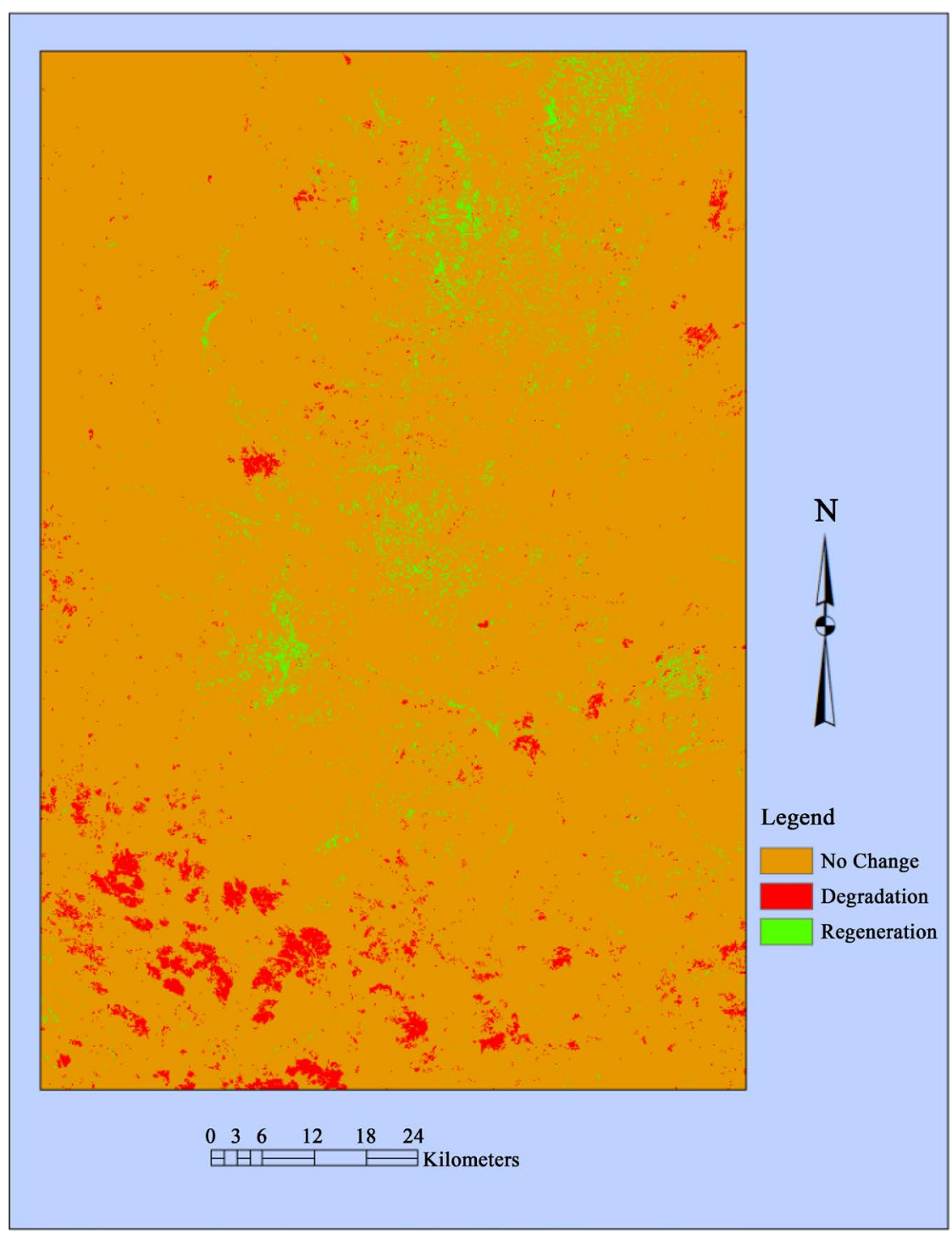

Figure 3. Difference image between 1999 and 2015.

\section{Recommendations}

The study has shown that the region is undergoing degradation at an unsustainable rate which may likely disrupt the ecological functioning of the ecosystem in the region. Therefore the study recommends urgent attention on conservation of the remaining vegetal resources in order to preserve the valuable assets of flora and fauna that are indigenous to the area. This can be done by ensuring strict compliance with rules and regulations guiding conservation in the country. Efforts should also be geared towards enlightenment of the communities on the benefits of vegetation and the need for conservation in the ecosystem. Restoration project should also be encouraged in areas already degraded.

\section{Conclusion}

The study used regression differencing method of change detection to elucidate the changes in vegetation cover in Mubi region. The results show that vegetation cover in the region is experiencing degradation. This is so because areas of vegetation degradation are expanding while areas of regeneration are dwindling. This trend is unhealthy to the region's ecosystem as it will lead to disruption of the functioning of the ecological system thereby affecting the habitats and consequently leading to biodiversity loss. Such trend creates a vicious cycle of 
continuous degradation which eventually affects the socio-economic wellbeing of the people residing in the region. Therefore, there is an urgent need for restoration and conservation of vegetation cover in the region.

\section{References}

[1] Birgit, R., Annette, O. and Rainer, W. (2007) Identifying of Land-Cover Change and Their Attributes in a Marginal European Landscape. Landscape and Urban Planning, 81, 104-133. http://dx.doi.org/10.1016/j.landurbplan.2006.10.018

[2] Barraclough, S.L. and Ghimire, K.B. (1996) Deforestation in Tanzania: Beyond Simplistic Generalizations. The Ecologist, 26, 104-107.

[3] Hatchinson, C.F., Unru, J.D. and Bahre, C.J. (2000) Land Use vs. Climate as Causes of Vegetation Change: A Study in SE Arizona. Global Environmental Change, 10, 47-55. http://dx.doi.org/10.1016/S0959-3780(00)00009-1

[4] Bahre, C.J. and Shelton, M.L. (1993) Historic Vegetation Change, Mesquite Increases, and Climate in Southeastern Arizona. Journal of Biogeography, 20, 489-501. http://dx.doi.org/10.2307/2845722

[5] Turner, B.L., Skole, D., Sanderson, S., Fischer, G., Fresco, L.O. and Leemans, R. (1995) Land Use and Land Cover Change. Science/Research Plan, IGBP Report No. 35, Stockholm 6, Geneve.

[6] Tucker, C.J., Dregne, H.E. and Newcomb, W.W. (1991) Expansion and Contraction of the Sahara Desert from 1980 to 1990. Science, 253, 229-301. http://dx.doi.org/10.1126/science.253.5017.299

[7] Hare, F.K. (1985) Climate Variations, Drought and Desertification. WMO, Geneva.

[8] Snrech, S. (1994) Population, environnement et economie au Sahel. In: Reenberg, A. and Markussen, B., Eds., The Sahel: Population; Integrated Rural Development Projects; Research Components in Development Projects, Proceedings from the Danish Sahel Workshop, 6-8 January 1994. AAU Reports 32. Aarhus University, Denmark.

[9] Webber, P. (1996) Agrarian Changes in Kusasi, North-East Ghana. Africa, 66, 437-457. http://dx.doi.org/10.2307/1160961

[10] Vierich, H.I.D. and Stoop, W.A. (1990) Changes in West African Savanna Agriculture in Response to Growing Population and Continuing Low Rainfall. Agriculture, Ecosystems and Environment, 31, 115-132.

http://dx.doi.org/10.1016/0167-8809(90)90214-X

[11] Greenland, D.J., Bowen, G., Eswaran, H., Rhoades, R. and Valentin, C. (1994) Soil, Water, and Nutrient Management Research-A New Agenda. IBSRAM Position Paper, Bangkok.

[12] Sala, O.E., Chapin, F.S., Armesto, J.J., Berlow, E., Bloomfield, J., Dirzo, R., Huber-Sanwald, E., Huenneke, L.F., Jackson, R.B., Kinzig, A., Leemans, R., Lodge, D.M., Mooney, H.A., Oesterheld, M., Poff, N.L., Sykes, M.T., Walker, B.H., Walker, M. and Wall, D.H. (2000) Biodiversity: Global Biodiversity Scenarios for the Year 2100. Science, 287, 1770-1774. http://dx.doi.org/10.1126/science.287.5459.1770

[13] Reid, R.S., Kruska, R.L., Muthui, N., Taye, A., Wotton, S., Wilson, C.J. and Mulatu, W. (2000) Land-Use and LandCover Dynamics in Response to Changes in Climatic, Biological and Socio-Political Forces: The Case of Southwestern Ethiopia. Landscape Ecology, 15, 339-355. http://dx.doi.org/10.1023/A:1008177712995

[14] Alphan, H. (2003) Land Use Change and Urbanization in Adana, Turkey. Land Degradation and Development, 14, 575-586. http://dx.doi.org/10.1002/ldr.581

[15] Muttitanon, W. and Tripathi, N.K. (2005) Land Use/Cover Changes in the Coastal Zone of Bay Don Bay, Thailand Using Landsat 5 TM Data. International Journal of Remote Sensing, 26, 2311-2323. http://dx.doi.org/10.1080/0143116051233132666

[16] Evrendilek, F. (2004) An Inventory-Based Carbon Budget for Forest and Woodland Ecosystems of Turkey. Journal of Environmental Monitoring, 6, 26-30. http://dx.doi.org/10.1039/b309893a

[17] Houghton, R.A. (2003) Revised Estimates of the Annual Net Flux of Carbon to the Atmosphere from Changes in Land Use and Land Management 1850-2000. Tellus B, 55, 378-390. http://dx.doi.org/10.1034/j.1600-0889.2003.01450.x

[18] Musa, A.A. and Adebayo, A.A. (2004) Environmental Degradation. In: Adebayo, A.A., Ed., Mubi Region: A Geographical Synthesis, Paraclete Publishers, Yola, 49-55.

[19] Saidu, I. and Gadiga, B.L. (2004) Population. In: Adebayo, A.A., Ed., Mubi Region: A Geographical Synthesis, Paraclete Publishers, Yola, 117-119.

[20] Adebayo, A.A., Ed. (2004) Mubi Region: A Geographical Synthesis. Paraclete Publishers, Yola.

[21] Lu, D., Mausel, P., Brondízio, E. and Moran, E. (2004) Change Detection Techniques. International Journal of Remote Sensing, 25, 2365-2401. http://dx.doi.org/10.1080/0143116031000139863

[22] Pu, R., Gong, P., Tian, Y., Miao, X., Carruthers, R.I. and Anderson, G.L. (2008) Using Classification and NDVI Differencing Methods for Monitoring Sparse Vegetation Coverage: A Case Study of Saltcedar in Nevada, USA. Interna- 
tional Journal of Remote Sensing, 29, 3987-4011. http://dx.doi.org/10.1080/01431160801908095

[23] Eastman, J.R. (2009) IDRISI Taiga Guide to GIS and Image Processing. Clark Labs, Clark University, Worcester.

[24] Orimooguje, O.O. and Gadiga, B.L. (2011) Remote Sensing for Mapping Riparian Vegetation Change in the Upper Yedzeram Basin. In: Salami, A.T. and Orimoogunje, O.O.I., Eds., Environmental Research and Challenges of Sustainable Development in Nigeria, Obafemi Awolowo University Press, Ile-Ife.

[25] Peter, Y., Gadiga, B.L. and David, N.F. (2015) Analysis of the Spatio-Temporal Dynamics of Mubi Area, Adamawa State, Nigeria. Adamawa State University Journal of Scientific Research, 3, 9-19. 